\title{
Correction to: On Orthogonal Projections for Dimension Reduction and Applications in Augmented Target Loss Functions for Learning Problems
}

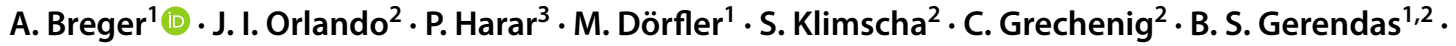 \\ U. Schmidt-Erfurth ${ }^{2} \cdot$ M. Ehler ${ }^{1}$
}

Published online: 25 November 2019

(c) The Author(s) 2019

\section{Correction to: Journal of Mathematical Imaging and Vision https://doi.org/10.1007/s10851-019-00902-2}

The article was originally published by the journal with an incorrect title. The correct title is given below:

"On Orthogonal Projections for Dimension Reduction and Applications in Augmented Target Loss Functions for Learning Problems". This has been corrected with this erratum.

The original article has been corrected.
Open Access This article is distributed under the terms of the Creative Commons Attribution 4.0 International License (http://creativeco mmons.org/licenses/by/4.0/), which permits unrestricted use, distribution, and reproduction in any medium, provided you give appropriate credit to the original author(s) and the source, provide a link to the Creative Commons license, and indicate if changes were made.

Publisher's Note Springer Nature remains neutral with regard to jurisdictional claims in published maps and institutional affiliations.

The original article can be found online at https://doi.org/10.1007/ s10851-019-00902-2.

A. Breger

anna.breger@univie.ac.at

1 Department of Mathematics, University of Vienna, Vienna, Austria

2 Department of Ophthalmology, Medical University of Vienna, Vienna, Austria

3 Department of Telecommunications, Brno University of Technology, Brno, Czech Republic 